\title{
ORDENAMENTOS TERRITORIAIS NA SUB-BACIA DO RIBEIRÃO DA VELHA, BLUMENAU (SC)
}

\author{
TERRITORIAL SYSTEMS ON THE SUB-BASIN OF RIBEIRÃO DA \\ VELHA, BLUMENAU CITY, SANTA CATARINA STATE
}

\author{
Jonathan Kreutzfeld ${ }^{1}$ \\ Maria Paula Casagrande Marimon ${ }^{2}$
}

\begin{abstract}
RESUMO
Este artigo visa apresentar o processo de ocupação da sub-bacia do Ribeirão da Velha. Para tanto, foram levantadas as informações sobre os ordenamentos territoriais que contribuíram para a sua ocupação e consultados documentos antigos, legislação e planos diretores. A área estudada, devido aos problemas hidrológicos pelos quais passava, teve seus ordenamentos alterados pelas emergências provenientes dessas intempéries. O Ribeirão da Velha está sob a influência de ordenamentos territoriais desde 1850, quando surgiu a colônia de Blumenau e, a partir de 1977, passou a ser regido por planos diretores.
\end{abstract}

Palavras-chave: Ordenamentos territoriais; Urbanização; Hidrografia; Blumenau; Ribeirão da Velha.

\begin{abstract}
This Article is intended to present the way how occurred the occupation of the sub-basin of Ribeirão da Velha, in Blumenau City, Santa Catarina State. To reach this goal, it was gathered the information referent to the territorial system that acted in your occupation. Old documents, legislation and master plans were consulted. The studied area suffers with hydrological problems and had your systems related with the emergencies of this issue. Ribeirão da Velha is under influence of territorial systems since the appearance of the colony of Blumenau in 1850 and from 1977 is governed by master plans.
\end{abstract}

Keywords: Territorial systems; Urbanization; Hydrograph; Blumenau; Ribeirão da Velha.

\section{A localização e ocupação da Região do Vale do Itajaí}

A bacia do Rio Itajaí, a maior contida inteiramente no estado de Santa Catarina, possui área correspondente a 16,5\% do território catarinense, onde vivem atualmente mais de um milhão de habitantes (FUNDAÇÃO AGÊNCIA DE ÁGUA DO ITAJAÍ, 2006, p. 10). De acordo com o Censo de 2010, 1.514.312 pessoas residem nesta área (IBGE, 2010).

O Ribeirão da Velha (Figura 1), uma das 52 sub-bacias da bacia do Rio Itajaí, compreende uma área de 55,65 $\mathrm{km}^{2}$ - que se estende em área urbana desde a região do extremo oeste do município de Blumenau -, cuja foz se situa no centro da cidade e o canal principal mede aproximadamente $10 \mathrm{~km}$ de extensão. Atualmente, nesta sub-bacia vivem

\footnotetext{
${ }^{1}$ Mestre em Planejamento Territorial e Desenvolvimento Socioambiental (MPPT) pela Universidade do Estado de Santa Catarina (UDESC).

2 Professora do Mestrado Profissional em Planejamento Territorial e Desenvolvimento Socioambiental (MPPT) da Universidade do Estado de Santa Catarina (UDESC).
} 
cerca de 60 mil habitantes, dos quais 56\% residem na área urbana e 44\%, na área rural (IBGE, 2010).

Figura 1 - Localização da sub-bacia do Ribeirão da Velha, município de Blumenau
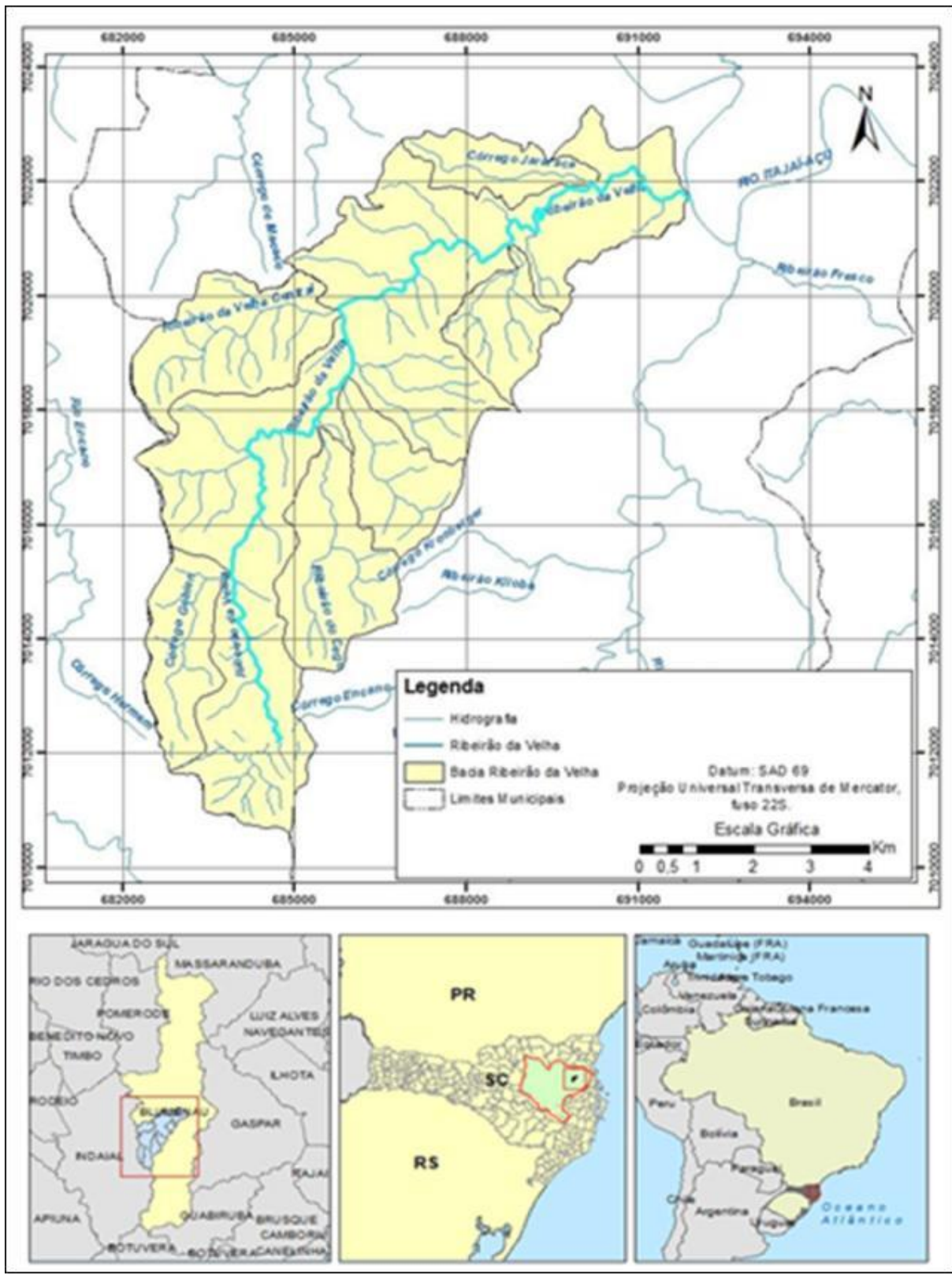

A ocupação da sub-bacia do Ribeirão da Velha é parte da história da cidade de Blumenau, que se inicia com a fundação da colônia pelo filósofo alemão dr. Hermann Bruno Otto Blumenau, e estava situada em uma região até então habitada pelos povos indígenas Kaigangs, Xoklengs e Botocudos.

Em 1850, dr. Blumenau obteve do Governo Provincial uma área de terras de duas léguas $^{3}$ para estabelecer uma colônia agrícola de imigrantes alemães (SANTIAGO, 2001). No

\footnotetext{
${ }^{3}$ A légua imperial equivale a aproximadamente $24 \mathrm{~km}^{2}$.
} 
dia 2 de setembro desse mesmo ano, ele e mais dezessete colonos chegaram ao terreno original da cidade de Blumenau e, nos anos seguintes, milhares de imigrantes desembarcaram dos veleiros de companhias particulares (SANTIAGO, 2001, p. 21) e ocuparam os lotes, já medidos e demarcados, ao longo dos rios e ribeirões que banhavam o território da concessão.

Até 1860, quando o Governo Imperial encampou o empreendimento do dr. Blumenau, a colônia era de propriedade dele. A partir daí, ele permaneceu ali como diretor, até a elevação da colônia à categoria de município, em 1880. Em poucos anos, dr. Blumenau transformou Blumenau em um dos maiores empreendimentos colonizadores da América do Sul, tornando-a um importante centro agrícola e industrial relevante na economia do País.

Desde a sua fundação, a colônia foi o centro irradiador de desenvolvimento para os municípios no seu entorno. Concomitante à atividade agrícola de subsistência, com a comercialização dos seus excedentes, florescia uma industrialização pujante, principalmente a indústria têxtil - com destaque para a Cia Hering (THEIS, 2007). No Vale, como a bacia é conhecida localmente, desde então encontram-se três setores econômicos de grande diversidade: a produção agropecuária e de exploração florestal, concentrada no Alto Vale, as atividades industriais no Médio Vale e as atividades de serviços no Baixo Vale.

Nessa bacia, situam-se atualmente 47 municípios e parte de mais 11 municípios (FUNDAÇÃO AGÊNCIA DE ÁGUA DO VALE DO ITAJAÍ, 2006, p. 10), onde verifica-se uma série de problemas socioeconômicos e ambientais decorrentes das migrações internas (de áreas rurais para as urbanas) e externas (provenientes de outras regiões ou ainda de outros estados) em busca de trabalho e melhores condições de vida.

A Lei $\mathrm{n}^{\circ} 860$, de 4 de fevereiro de 1880 , alçou a colônia à categoria de município (SANTIAGO, 2001, p. 24). Contudo, em outubro daquele mesmo ano, uma grande inundação destruiu pontes e estradas, causando sérios prejuízos à população e à administração pública, e a instalação do município só foi possível no dia 10 de janeiro de 1883 , quando a Câmara Municipal eleita no ano anterior assumiu o exercício. Três anos depois, o município recebeu o título de comarca e, finalmente, em 1928, passou à categoria de cidade.

Até 1934, o território de Blumenau ocupava uma área de $10.610 \mathrm{~km}^{2}$, e hoje se resume a $526 \mathrm{~km}^{2}$ (IBGE, 2010). Trinta e oito novos municípios resultaram de sucessivos desmembramentos do território.

\section{Aspectos econômicos e de ocupação da região do bairro da Velha}

A ocupação do bairro da Velha integrou a formação da cidade de Blumenau e se deu com a divisão de lotes, conforme determinado pela Lei de Terras do Governo Imperial. Cada lote media 200 morgos $^{4}$, era ribeirinho e tinha seu tamanho calculado a partir do ribeirão. Porém, devido à altimetria bastante acidentada da região, promoveu-se também a ocupação de morros (DICKMANN, 2002, p. 11).

As terras de abrangência do atual bairro da Velha pertenceram ao colonizador da cidade, dr. Hermann Otto Bruno Blumenau, até 1879, quando parte delas foi vendida a Gustav Stutzer (DICKMANN, 2002, p. 12). O fato de o dr. Blumenau ter mantido sem uso boa parte

\footnotetext{
${ }^{4}$ Morgo = medida de área territorial equivalente a $2.500 \mathrm{~m}^{2}$. Trata-se de expressão utilizada principalmente no litoral norte de Santa Catarina, em áreas de colonização alemã, polonesa e italianos do norte. Quatro morgos equivalem a um hectare.
} 
dessas terras, já que as possuía com finalidade especulativa, prejudicou o desenvolvimento da área.

Quando Stutzer começou a venda de lotes de suas terras, em 1885, a primeira rua do bairro da Velha foi aberta em meio à mata, e isso contribuiu muito para a ampliação da ocupação da área. Atualmente essa rua chama-se João Pessoa e termina onde até hoje se encontra a "Casa Tomio". Mais de 30 famílias fixaram-se nas imediações da rua, o que ocasionou a intensificação dos confrontos com os indígenas. Muitas mortes e prejuízos socioeconômicos ${ }^{6}$ ocorreram até a pacificação em 1914. Inúmeros relatos desses confrontos foram narrados por Therese Stutzer, esposa de Gustav (HUBER, 2010, p. 27).

As famílias imigrantes prosperaram através de comércios e empresas de diversos ramos, e muitos dos que chegaram posteriormente buscaram empregos nas empresas já estabelecidas. Porém, a economia desenvolve-se principalmente a partir de 1915, quando a região da Velha passou a ter energia elétrica graças à usina hidrelétrica do Salto (DICKMANN, 2002, p. 15), enquanto que o restante da cidade já dispunha desse recurso desde 1909. Já a água encanada surge apenas em 1943 - até então, muitas famílias se dessedentavam em poços e nascentes.

Theis (2007), em seu trabalho sobre a formação econômica de Blumenau, destaca três fases na industrialização da cidade, que podem ser aplicadas à formação econômica da região da Velha: a primeira entre 1883 e 1914, a segunda entre 1914 e 1945 e a terceira após 1945. Na primeira fase, não havia indústrias instaladas porque não existia energia elétrica e os lotes foram tardiamente vendidos; na segunda fase, algumas empresas, sobretudo têxteis, se instalaram; e na terceira fase, a implantação de novas estradas e ruas, meios de transporte, água tratada e telefone dinamizou a região.

Devido à sua dimensão relativamente grande, o bairro da Velha possui algumas subdivisões internas em bairros, tais como: Velha Central, Velha Grande, Velha Pequena, Ribeirão Branco, Água Branca e Água Verde (DICKMANN, 2002, p. 15). A formalização do bairro, juntamente com a de outros bairros da mesma região, ocorre oficialmente em 28 de abril de 1956, pelo então prefeito Frederico Guilherme Busch Júnior.

Com a constante expansão da região, surgiu a necessidade de transporte para os moradores e trabalhadores. O transporte público foi implantado a partir da década de 1940 (DICKMANN, 2002, p. 25), mas evoluiu muito lentamente até a década de 1990. Um dos fatores determinantes para a demora da implantação do transporte coletivo foi o seu elevado custo, devido às grandes distâncias e à precariedade das estradas. Isso implicou o uso de bicicletas como principal meio de locomoção da maior parte da população.

Na década de 1980, após as enchentes de 1983 e 1984, houve significativo aumento populacional no bairro e o surgimento de novos loteamentos, como Guaricanas, Girassol e Jardim Primavera. A favelização, bastante tardia se comparado a outras áreas da cidade, também se inicia nesse período (DICKMANN, 2002, p.13). Os vários ordenamentos

\footnotetext{
5 A Casa Tomio é uma loja de materiais de construção e decoração que existe desde o início da ocupação das terras dessa área do bairro. Hoje, o comércio ainda está ativo e é uma importante referência de localização. A loja fica localizada onde a população costuma dizer que "a Velha abre as pernas", pois a partir desse ponto onde a Rua João Pessoa termina, iniciam-se duas outras ruas importantes para o acesso ao bairro: Rua General Osório e Rua Governador Jorge Lacerda.

6 Therese Stutzer, esposa de Gustav Stutzer, relata que havia danos constantes em galpões, cisternas, carroças, entre outros prejuízos, tais como saques de mantimentos e ferramentas.
} 
territoriais da região da Velha ${ }^{7}$ beneficiaram imensamente o bairro. Hoje nele se encontram instaladas grandes indústrias, como Hering, Resima, Lancaster, Gráfica 43 e Blukit, a Sociedade Desportivo Vasto Verde e a Associação da Hering e escolas. Além disso, o bairro é palco da Oktoberfest, uma das maiores festas de cerveja do mundo e uma das mais populares festas folclóricas do Brasil.

Com mais de 40 mil habitantes, a região da Velha é a mais populosa da cidade de Blumenau (IBGE, 2010, p. 19). E somando-se a população dos bairros pertencentes à subbacia do Ribeirão da Velha, chega-se a um total de 69.244 habitantes (Tabela 1).

Tabela 1 - População residente por bairros na sub-bacia do Ribeirão da Velha

\begin{tabular}{lc}
\hline Bairro & $\mathbf{N}^{\mathbf{o}}$ de habitantes (2010) \\
\hline Água Verde & 16.186 \\
Velha & 15.373 \\
Velha Central & 18.779 \\
Velha Grande & 4.332 \\
Victor Konder & 4.612 \\
Vila Nova & 9.962 \\
Total & $\mathbf{6 9 . 2 4 4}$ \\
\hline
\end{tabular}

Fonte: IBGE (2010).

Para fins de comparação, é interessante observar que a população da sub-bacia do Ribeirão da Velha possuía, já na década de 1960, uma população superior à da cidade de Blumenau (Gráfico 1) e, atualmente, representa 22,4\% da população do município.

A área circundante ao Ribeirão da Velha em Blumenau, em virtude do seu grande crescimento socioeconômico, tornou-se mais urbanizada, porém, mais sujeita a enchentes e enxurradas, uma vez que a construção de ruas calçadas, pátios cimentados, telhados, etc., torna o solo mais impermeável à infiltração das águas da chuva. A parcela de água que antes penetrava a terra verte agora pelos condutos, aumentando o volume do escoamento superficial e reduzindo o tempo de chegada das águas das chuvas aos leitos dos rios, e disso decorre a ampliação das ocorrências de enchentes e enxurradas (TUCCI, 1995, p. 17).

\footnotetext{
${ }^{7}$ Plano Diretor de 1977 e suas revisões: a de 1989 direcionou o crescimento da população para a região oeste (área de abrangência da bacia do Ribeirão da Velha); a de 1997 promoveu o crescimento para as regiões norte e ainda mais para o oeste da cidade; e o de 2006 visou ao desenvolvimento da urbanização da região oeste e ao fortalecimento da ocupação da região norte, tirando o "foco" da região da Grande Velha.
} 
Gráfico 1 - Evolução populacional do Município de Blumenau (1950-2010)

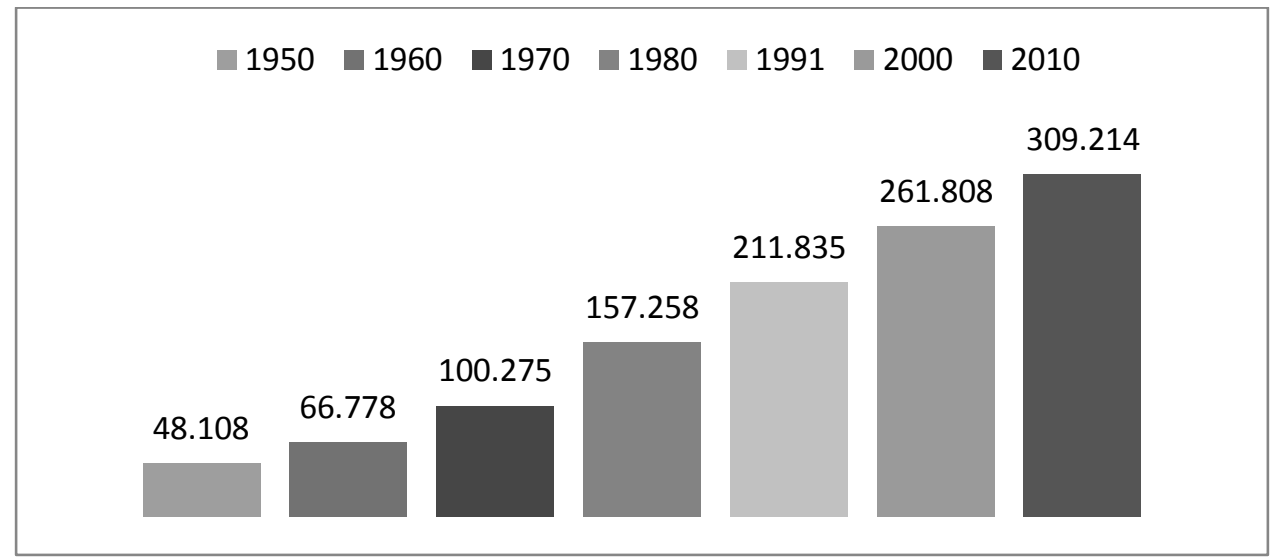

Fonte: IBGE (2010).

\section{Ordenamentos territoriais e sua relação com os eventos hidrológicos}

Diante do exposto, é oportuno compreender detalhadamente o desenvolvimento da cidade desde a sua origem, e, a partir dele, o do bairro da Velha.

A evolução da malha urbana de Blumenau tem características de expansão radial (PMB, 2009), em razão de dois fatores: a origem colonial e a topografia bastante acidentada. Segundo Souza (2008), existem princípios gerais reguladores do número, tamanho e distribuição dos núcleos de povoamento: grandes, médias e pequenas cidades, todas são consideradas localidades centrais e dotadas de funções centrais, isto é, atividade de distribuição de bens e serviços para a população externa (residente na região complementar) em relação à qual a localidade central tem uma posição crucial. A centralidade de um núcleo, por sua vez, refere-se ao grau de importância conforme as funções desempenhadas: quanto maior o número delas, maior a sua área de influência, maior a população atendida pela localidade central e maior a sua centralidade. No caso de Blumenau, sua fundação e desenvolvimento estão diretamente relacionados às condições naturais e de navegabilidade do rio, dado que "o sítio urbano se refere à última parte navegável para o Vapor Blumenau. $\mathrm{O}$ Rio Itajaí tinha limitações a partir daquele ponto de encontro com o Ribeirão Garcia" (PMB, 1996).

A cidade teve origem no terceiro quarto do século XIX e se constituía de lotes coloniais de mil metros de profundidade, a partir dos leitos de rios e ribeirões, e com aproximadamente 250 metros de testada. No decorrer do tempo, esse modelo revelou-se inviável, pois implicava grandes deslocamentos diários no sentido periferia-centro e centroperiferia. Conforme Santos (1980), “[...] não existe homogeneidade do espaço, como também não existe homogeneidade das redes." Assim, a malha urbana de Blumenau desenvolveu-se de forma desigual - constituindo-se em um fator determinante para que houvesse mais infraestrutura para a região central em detrimento das regiões periféricas -, e para dar uniformidade à rede urbana, fazia-se então necessário um planejamento. Contudo, a heterogeneidade não deve ser considerada geradora de desordem e desorganização, pois pode estabelecer pontos de contato para o fortalecimento das relações desiguais. Essa condição desigual e combinada abre um espaço significativo para o emprego da hierarquia urbana.

Além disso, a expansão territorial no entorno das margens dos rios, embora beneficiasse a agricultura e facilitasse o escoamento da produção agrícola, acarretava também prejuízos em função das enchentes. 
O mapa da colônia de Blumenau de 1864 (Figura 2) mostra o Ribeirão da Velha originalmente. Como supracitado, a área foi a última a ser vendida pelo dr. Blumenau e, consequentemente, a última a ser loteada como colônia.

O mapa cadastral de Blumenau de 1928 (Figura 3) já apresenta uma nova divisão dos lotes coloniais, perfazendo 71 lotes em torno do Ribeirão da Velha. Naquele período, como já havia maior conhecimento geográfico do munícipio - o que possibilita a ampliação da escala do cadastramento -, as outras áreas loteadas anteriormente foram fracionadas em lotes menores.

No período entre 1864 e 1928, Blumenau deixa de ser colônia, vira distrito (1873), depois vila (1883) e, em 1894, é alçada à condição de cidade pela Lei no 197 (Santa Catarina, 1894). Na divisão administrativa referente ao ano de 1911, o município de Blumenau constitui-se de três distritos: Blumenau, Indaial e Gaspar.

Figura 2 - Mapa da colônia de Blumenau, em 1864

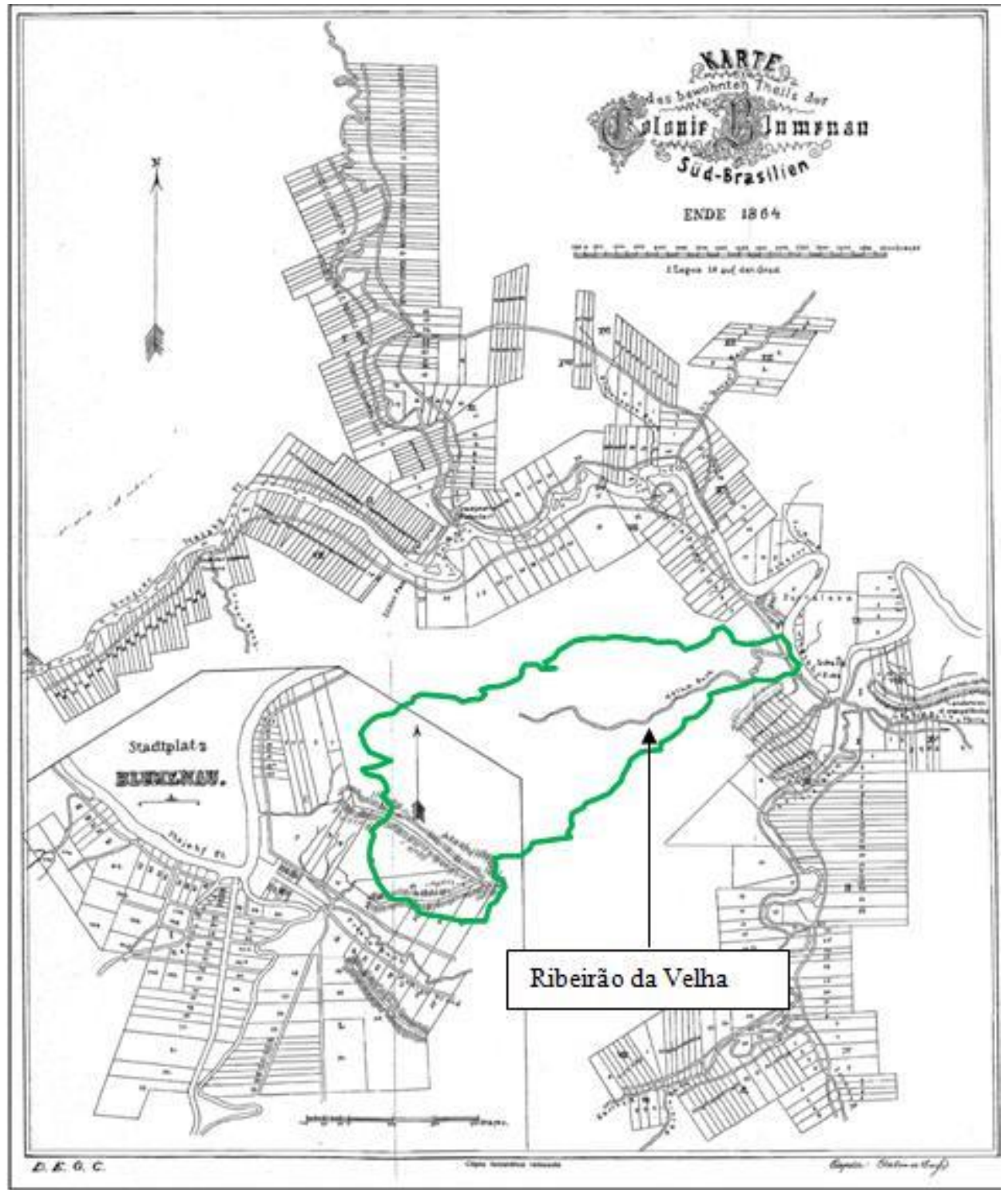

Fonte: Arquivo Histórico de Blumenau (Adaptado). 
Figura 3 - Reprodução do Mapa Cadastral de Blumenau, em 1928

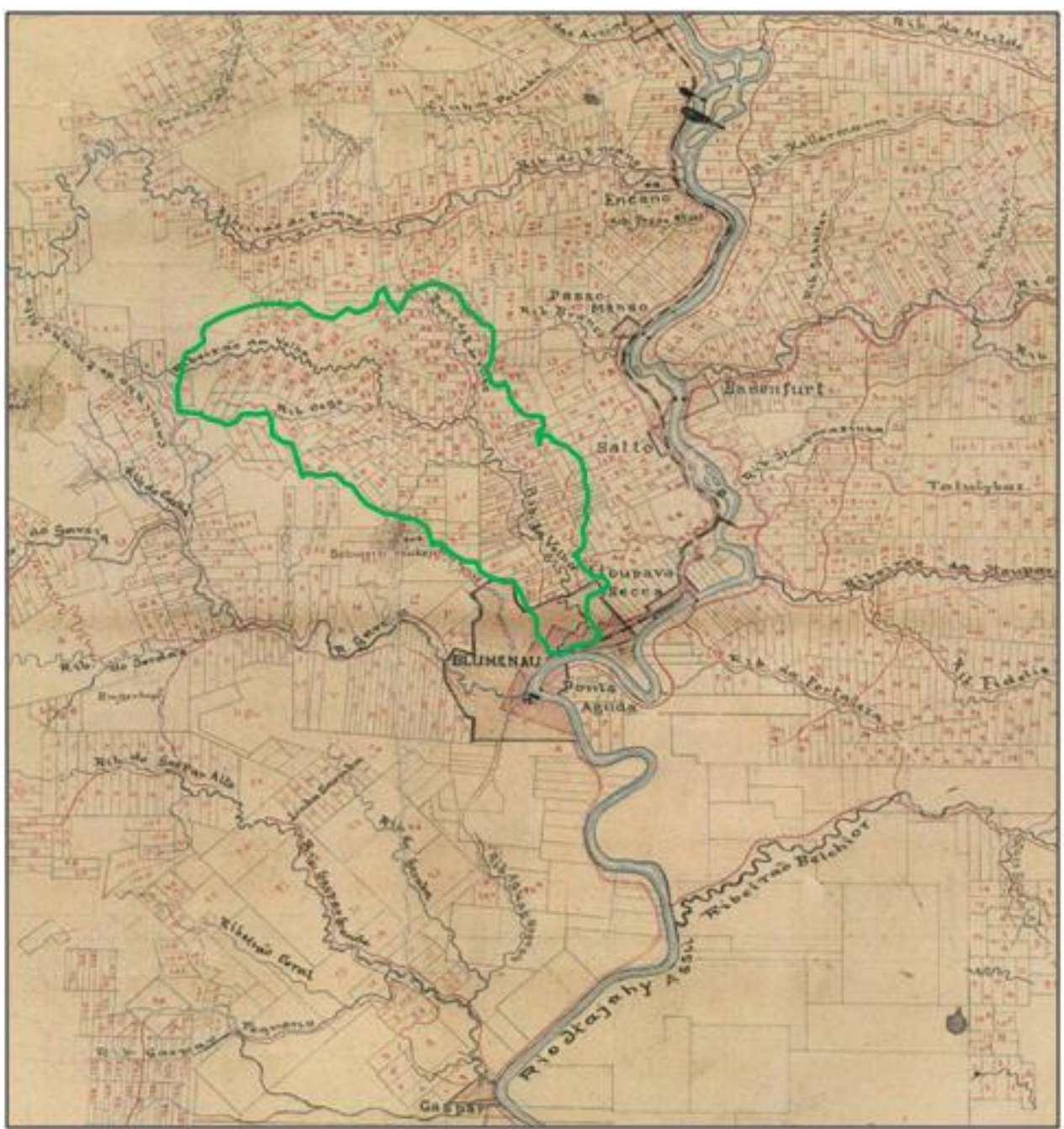

Fonte: Arquivo Histórico de Blumenau (Adaptado).

Em 1928, já havia plantas da cidade com escala de 1:25000 (Figura 4), nas quais é possível, pela primeira vez, observar detalhadamente a ocupação da margem direita do Rio Itajaí, onde se encontra a bacia do Ribeirão da Velha, e verificar a altimetria, o arruamento e a hidrografia. 
Figura 4 - Reprodução de planta da margem direita do Rio Itajaí-Açú, em 1968

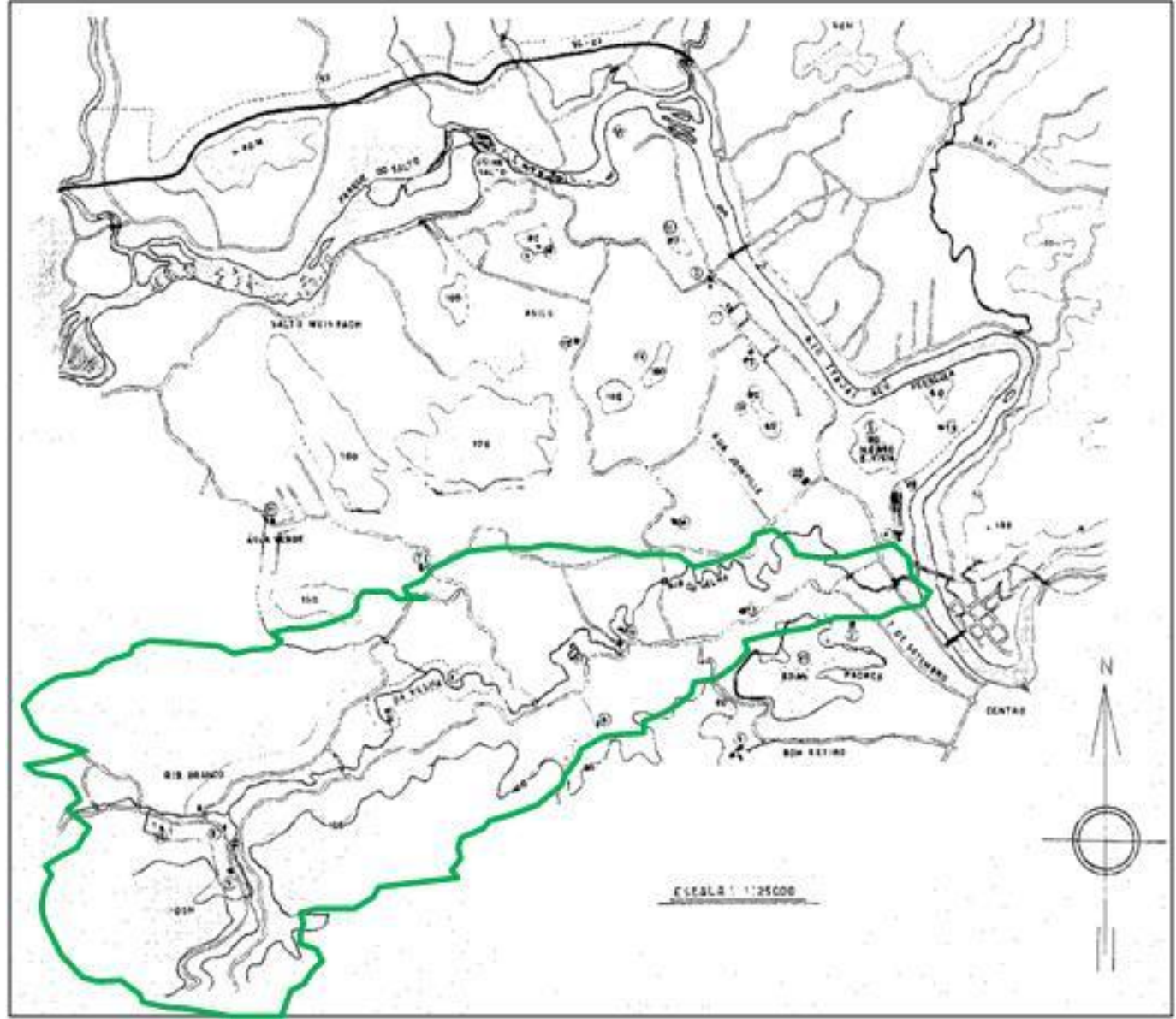

Fonte: Arquivo Histórico de Blumenau (Adaptado).

\subsection{Os planos diretores}

O município de Blumenau teve historicamente uma centralidade urbana muito acentuada e ocupação do espaço rural mais esparsa. Para inverter esse processo, elaborou-se o primeiro plano diretor do município (Plano Diretor de 1977). Revisado pela primeira vez em 1989, o Plano tinha agora novos desafios de planejamento e ordenamento territorial, relacionados às enchentes de 1983 e 1984. Para suprir as necessidades de serviços, que dependiam ainda do centro da cidade, no Plano de 1997 foram criados subcentros com o objetivo de ampliar os corredores de serviços; porém, devido à falta de investimentos, isso não aconteceu. A última revisão realizada no plano diretor ocorreu em 2006, visando principalmente à integração dos investimentos, dos serviços públicos e da ocupação do solo. $\mathrm{O}$ intuito, mais uma vez, foi o de se tentar sanar as deficiências urbanas ainda existentes no município (PMB, 2008, p.12).

Nesse contexto, é importante também considerar a situação demográfica do município de Blumenau e sua evolução, a partir da década de 1950. Os dados censitários de então já destacavam que mais da metade da população do município morava em áreas urbanas - o que demonstra a sua importância -, e os dados do censo de 2010 contabilizam uma população de 297.595 habitantes, dos quais 95,5\% residem na área urbana e 4,5\%, na área rural. 
Em 2010, a Prefeitura de Blumenau divulgou um relatório sobre os dados preliminares do Censo 2010, que possibilitam uma compreensão da dinâmica demográfica do município entre 1950 e 2010.

Similaridade ao modelo nacional, o município de Blumenau vem passando por um processo de urbanização intensa desde 1950, ano em que a população dividia-se igualmente entre urbana e rural. Em 2000, já se verifica uma diferença significativa: 92,4\% da população concentrava-se na cidade e apenas 7,6\%, na área rural. E, em 2010, observa-se um aumento da taxa populacional urbana de $3,1 \%$ (de $92,4 \%$ para $95,5 \%$ ), que decorre da ampliação da área urbana, através da Lei Complementar $\mathrm{n}^{\circ} 489$, de 25 de novembro de 2004, que fixou o novo perímetro urbano do município de Blumenau (sede do Distrito de Vila Itoupava) e estabeleceu a nova divisão de bairros (PMB, 2010).

Abaixo, são descritos os planos diretores do município de Blumenau que constituem os principais instrumentos de ordenamento territorial da cidade.

\subsubsection{Plano de $1977^{8}$}

Com o parcelamento contínuo dos lotes coloniais, as regiões centrais foram se adensando, tanto em relação à ocupação do solo quanto ao aumento populacional. Os espaços vazios foram sendo eliminados, embora fosse bastante comum encontrar, até a década de 1970, pastagens dentro da malha urbana. As regiões periféricas tinham grande dependência da área central, era difícil estabelecer a formação de subcentros, a horizontalidade predominava na ocupação das periferias, e sempre margeando os ribeirões da cidade. E como menciona Dickmann (2002, p.13), o surgimento da Rua João Pessoa, que foi aberta em meio à mata, contribuiu muito para o desenvolvimento da região da Velha.

De acordo com o Plano Diretor de 1977, o uso do solo para fins comerciais acontece principalmente na área central e com menor intensidade nas vias arteriais, formando os corredores de serviço. Vale relembrar que a Rua João Pessoa tornou-se um dos principais corredores, margeando o Ribeirão da Velha, constituindo-se, assim, um importante elo entre o centro e a periferia da região oeste da cidade. As características centralizadoras, associadas à inexistência de subcentros bem definidos nos bairros, geraram conflitos entre pedestres e veículos, os quais prejudicavam inclusive o fluxo do transporte coletivo, que já existia desde a década de 1940, mas que prestava o serviço precariamente, não obstante a grande demanda da população por transporte.

O uso do solo para fins industriais é raro na malha urbana, pois, logo no início da implantação da cidade, foram construídas diversas estradas ligando as vilas aos outros municípios. Com o crescimento da atividade industrial, houve um aumento significativo de oportunidades de emprego, e a possibilidade de se residir perto do trabalho, além de representar uma diminuição do tempo de deslocamento casa-trabalho, também significava uma redução das despesas com transporte coletivo, tendo em vista o alto custo para as áreas mais longínquas. Porém, a atividade industrial crescente também trouxe como consequência problemas socioambientais mais acentuados, prejudicando a população residente local.

Em decorrência das enchentes ocorridas na década de 1980, o planejamento da cidade se voltou às áreas que, à princípio, não eram tão suscetíveis às cheias. Houve então a

\footnotetext{
${ }^{8}$ Lei n ${ }^{\text {o } 2242, \text { de }} 30$ de maio de 1977, de Blumenau.
} 
verticalização e a troca do uso residencial para comercial nas áreas mais baixas, sob ameaça de eventos de alagamentos e enchentes.

\subsubsection{Plano de 19899}

Esse plano diretor direcionou o crescimento da cidade principalmente para as zonas oeste do município (Vale do Ribeirão da Velha), norte (com a ocupação do vale dos ribeirões Itoupava e Salto) e noroeste (Vale do Ribeirão Fortaleza).

Entre 1970 e 1990, o contingente de imigrantes na cidade de Blumenau aumentou consideravalmente, em consequência do desenvolvimento econômico da cidade e região. Este aumento populacional obrigou parte dos habitantes a ocupar áreas de risco e de preservação ambiental (topo de morros, encostas íngremes e margem de rios), por causa do alto custo dos lotes urbanos regulares, agravando, assim, as condições de vida de parte da população da cidade.

Em síntese, a ocupação territorial, ao longo da história de Blumenau, aconteceu sempre em torno de seus principais recursos hidrográficos e, inicialmente, na direção oeste e sul. A partir da década de 1990, a ocupação voltou-se também para o norte, mantendo uma tendência de intensificação da urbanização no oeste e sul.

O Plano Diretor de 1989 também criou diversos corredores de serviço, abrangendo as principais vias de penetração de bairros, na tentativa de possibilitar o acesso ao comércio e aos serviços, sem a necessidade de deslocamento para o centro da cidade.

Apesar de as diretrizes visarem à “descentralização", a ocupação da região central da cidade continuou intensa, ocasionando aumento do tráfego no centro da cidade e nas próprias vias de penetração dos bairros.

\subsubsection{Plano de $1997^{10}$}

Essa revisão do plano diretor foi realizada por profissionais técnicos da própria Prefeitura, após estudos realizados durante os quatro anos anteriores à sua aprovação.

O Plano de 1997 se fundamenta na ocupação das regiões oeste e norte da cidade, com o argumento de que essas zonas possuem áreas disponíveis para urbanização, além de contar com áreas urbanizáveis de baixa suscetibilidade a eventos hidrológicos e escorregamentos.

Destacam-se nesta revisão a ampliação da região central, a proposta de continuar impulsionando o crescimento para as regiões norte e oeste (sub-bacia do Ribeirão da Velha), projetando-se novas vias e pontes, e as diretrizes para criação de sistema cicloviário. Vale ainda ressaltar que, pela primeira vez, houve a hierarquização de todo o sistema viário.

\footnotetext{
9 Lei no 3650/1989, de Blumenau.

10 Lei Complementar no 142/1997, de Blumenau.
} 


\subsubsection{Plano de $2006^{11}$}

Esse novo exame do plano diretor, já sob orientação do Estatuto das Cidades (2001), resultou de relatórios e diagnósticos produzidos pela equipe técnica da Secretaria de Planejamento Urbano do Município de Blumenau em conjunto com outras secretarias, que, após reuniões com a população, identificou os aspectos a ser contemplados no novo plano.

A partir da aprovação do Plano Diretor de 2006, está prevista a integração entre os investimentos e serviços públicos e a ocupação do solo. Para cumprir esses objetivos, foi criado o Projeto Blumenau 2050, que se subdivide em cinco eixos de atuação:

- $\quad$ Eixo 1 - Uso e ocupação do solo;

- Eixo 2 - Sistema de circulação e transporte;

- Eixo 3 - Intervenções para o desenvolvimento econômico, o turismo e o lazer;

- Eixo 4 - Habitação e regularização fundiária;

- Eixo 5 - Saneamento e meio ambiente.

Os eixos são analisados de acordo com suas condicionantes, deficiências e potencialidades, visando aplicar a cada item um procedimento adequado às demandas. $\mathrm{O}$ projeto também divide as ações em curto (até 2015), médio (até 2030) e longo prazo (2050).

No que diz respeito ao uso e ocupação do solo em Blumenau (Eixo 1), é possível verificar que a sub-bacia do Ribeirão da Velha está situada predominantemente em áreas de consolidação do desenvolvimento. Uma das preocupações diz respeito ao zoneamento das áreas de nascentes, que aparecem como áreas de restrição de ocupação, devido a riscos de escorregamentos e, por isso mesmo, constituem uma zona de adensamento urbano controlado.

É importante salientar que somente nesse plano diretor foi criado uma zona de restrição de uso por risco de enchente, tendo sido limitada à ocupação até a cota de 12 metros. Esta zona abrange parte da área de risco de enchente por remanso do Rio Itajaí, junto da área da foz do Ribeirão da Velha.

\section{Considerações finais}

Os ordenamentos territoriais que influenciaram a ocupação da sub-bacia do Ribeirão da Velha datam do período colonial e, em período recente, foram criados planos diretores norteadores. Contudo, estes ordenamentos não conseguiram intervir no modo tradicional de ocupação do espaço a partir de seus cursos de água e têm sofrido alterações emergenciais, por causa dos problemas hidrológicos. O mapa da Figura 5 auxilia na compreensão da forma de ocupação da terra ao longo dos ribeirões. As zonas sul e oeste da cidade têm se expandido, ainda que espontaneamente, tendo como fator indutor do crescimento os cursos de água locais.

A Figura 5 também mostra o crescimento da mancha urbana identificada na cidade, com base nos voos aerofotogramétricos de 1966, 1977, 1989 e 2003 (PMB). Ela ainda apresenta a bacia do Ribeirão da Velha como uma área do intenso desenvolvimento, a partir da década de 1990 - o que é reflexo principalmente da revisão do Plano Diretor de 1989. Devido às grandes enchentes de 1983 e 1984, esse Plano redirecionou a ocupação para áreas de menor incidência de enchentes, entre elas, a região da Velha.

$\mathrm{Na}$ Bacia do Ribeirão da Velha, a área urbana edificada, boa parte do sistema viário e, consequentemente, a ocupação do solo estão implantadas junto ao leito maior do ribeirão e

\footnotetext{
${ }^{11}$ Lei Complementar n ${ }^{\circ}$ 615/2006, de Blumenau.
} 
seus córregos (Figura 5). De acordo com Tucci (1997, p. 5), as enchentes em áreas urbanas têm mostrado aumento da frequência e magnitude, em consequência da ocupação do solo com a ampliação das superfícies impermeáveis e redes de condutos de escoamentos mal dimensionadas. Adicionalmente, o desenvolvimento urbano pode produzir obstruções ao escoamento das águas com a construção de aterros e pontes, drenagens inadequadas e outras oclusões junto a condutos e assoreamento dos cursos d'água. Todos esses tipos de ocorrência são também verificados na região da Velha.

Ainda na mesma Figura 5, é possível observar que o uso mais frequente da terra na bacia é o urbano e ocupa as áreas de mais baixas altitudes e declividades (planícies). Nota-se também que, nas zonas rurais, a vegetação de florestas em diferentes estágios de regeneração recobrem predominantemente as encostas. Os campos, pastagens e áreas de agricultura são pouco expressivos, mesmo na zona rural da bacia.

Figura 5 - Mapa do crescimento da mancha urbana de Blumenau 1966, 1978, 1993 e 2003
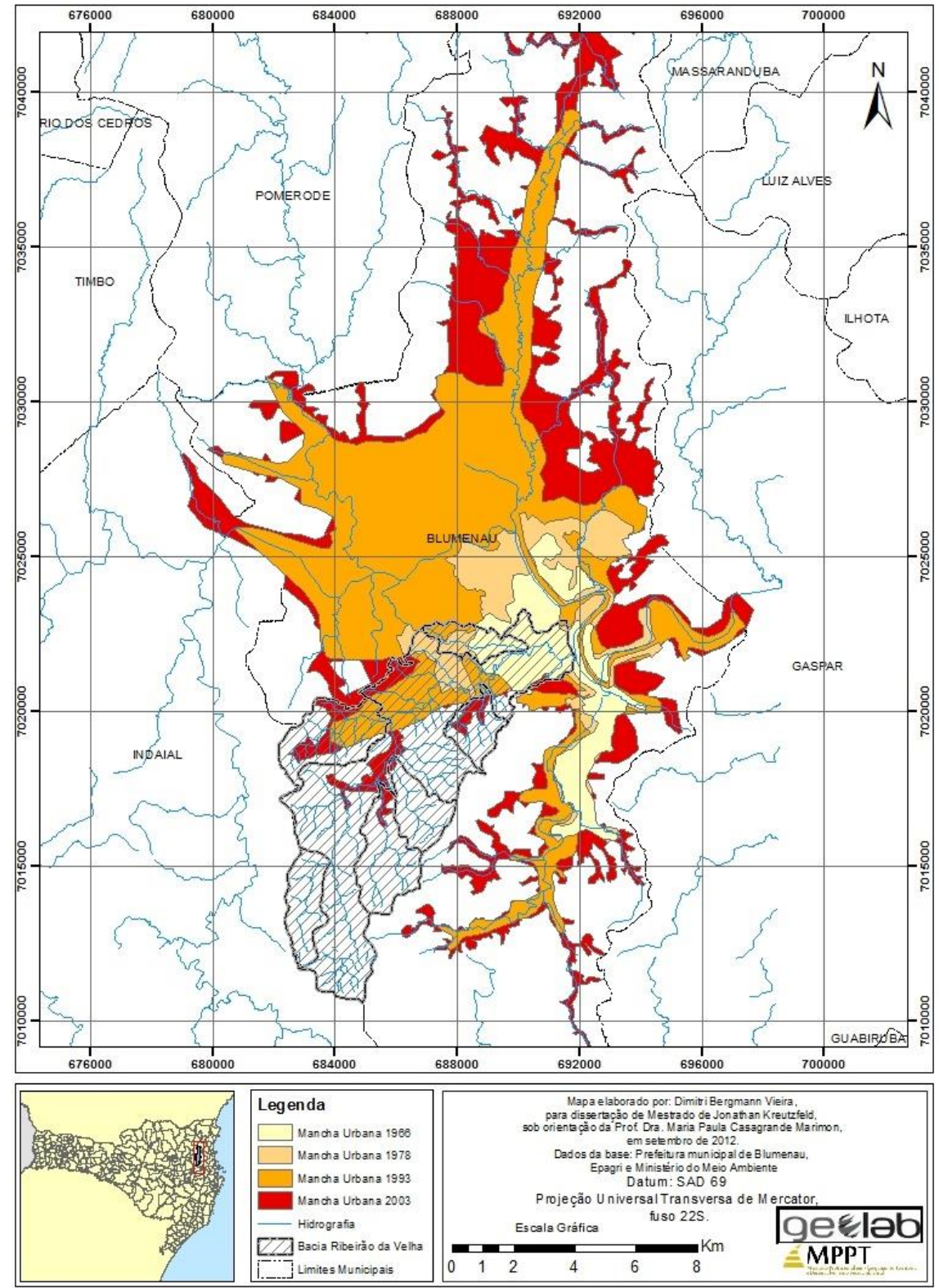


\section{REFERÊNCIAS}

DICKMANN, Márcia Regina. Velha: uma história. Blumenau: Odorizzi, 2002. 60 p.

HUBER, Valburga (Org.). Marie Luise Therese Stutzer. Blumenau: Cultura em Movimento, 2010. 114 p.

IBGE. Resultados Preliminares do Universo do Censo Demográfico, 2010.

IBGE. Sistema de Informações Gerenciais de Apoio à Decisão (SIGAD), 2010.

THEIS, Ivo Marcos. Formação de uma economia local: o caso de Blumenau. Blumenau em cadernos: edição especial 1957-2007. Blumenau: Cultura em Movimento, 2007. p.141-158.

FUNDAÇÃO AGÊNCIA DE ÁGUA DO VALE DO ITAJAÍ. Plano de recursos hídricos da bacia hidrográfica do Rio Itajaí: construindo o futuro da bacia. Blumenau: Fundação Agência de Água do Vale do Itajaí, 2006. 80 p.

PMB - PREFEITURA MUNICIPAL DE BLUMENAU. Blumenau 2050 - Revista do Programa de Desenvolvimento Urbano de Blumenau, Ano I, Número 1. SEPLAN, Blumenau. 2008. 43p

PMB - PREFEITURA MUNICIPAL DE BLUMENAU. Relatório Censo 2010 - Blumenau. Blumenau: SEPLAN, 2010. 4 p.

PMB - PREFEITURA MUNICIPAL DE BLUMENAU. Blumenau 2050 - Revista do Programa de Desenvolvimento Urbano de Blumenau Ano II, Número 2. Blumenau: SEPLAN, 2011. 71p

PMB - PREFEITURA MUNICIPAL DE BLUMENAU. Estudo de impacto de vizinhança: projeto executivo de engenharia rodoviária inclusive obras de arte especiais e estudos ambientais complementares do prolongamento da rua Humberto de Campos. Blumenau: SEPLAN, 2011. $402 \mathrm{p}$.

PMB - PREFEITURA MUNICIPAL DE BLUMENAU. Blumenau 2050 - Revista do Programa de Desenvolvimento Urbano de Blumenau Ano III, Número 3. Blumenau: SEPLAN, 2012. $41 \mathrm{p}$.

SANTIAGO, Nelson Marcelo. 100 anos construindo Blumenau. Blumenau: Expressão, 2001. $204 \mathrm{p}$.

SANTOS, Milton. A urbanização desigual. Petrópolis: Vozes, 1980.

SOUZA, Marcelo Lopes de. Mudar a Cidade: uma introdução crítica ao planejamento e gestão urbana. Rio de Janeiro: Bertrand Brasil, 2008.

TUCCI, Carlos Eduardo Morelli. Drenagem Urbana. Porto Alegre: ABRH, 1995. 428 p. 